\title{
DESIGN OF NEW CO-FLOW BURNER
}

\author{
by \\ Pascal Leung \\ Bachelor of Engineering, Ryerson University (2017)
}

\author{
A project \\ presented to Ryerson University \\ in partial fulfillment of the \\ requirements for the degree of \\ Master of Engineering \\ in the program of \\ Aerospace Engineering
}

Toronto, Ontario, Canada, 2020

C Pascal Leung 2020 


\section{AUTHOR'S DECLARATION FOR ELECTRONIC SUBMISSION OF A PROJECT}

I hereby declare that I am the sole author of this project. This is a true copy of the project, including any required final revisions.

I authorize Ryerson University to lend this project to other institutions or individuals for scholarly research.

I further authorize Ryerson University to reproduce this project by photocopying or by other means, in total or in part, at the request of other institutions or individuals for the purpose of scholarly research.

I understand that my project may be made electronically available to the public. 


\title{
DESIGN AND OF NEW CO-FLOW BURNER
}

\author{
Pascal Leung \\ Master of Engineering, Aerospace Engineering, Ryerson University, Toronto (2020)
}

\begin{abstract}
This report documents the design of a colinear flow burner and staging arrangements for the study of soot formations with Ryerson's clean energy and combustion research group.

Soot is a common product of combustion. Its pollutant forms of black carbon are significant contributors to radiative forcing and causes negative health effects. Soot within a flame can be located by the luminosity of the flame. The visible yellow, orange and red light released by a flame results from incandescent soot particles. For the purpose of studying soot a burner that provides a controllable nonpremixed laminar flame is required.

The proposed burner and surrounding set up is designed with as many off the shelf parts as possible limiting the need for custom machining to the burner body. The project consists of designing the burner body, arranging the staging for the burner and tables for the experiment instruments including the soot sensor camera.
\end{abstract}




\section{ACKNOWLEDGEMENTS}

I would like to thank my supervisor Dr Emre Karatas of the Department of Aerospace Engineering at Ryerson University. The opportunity to work with him and his research group was a valued learning experience. His help, patience and guidance throughout this project made it possible. 


\section{TABLE OF CONTENTS}

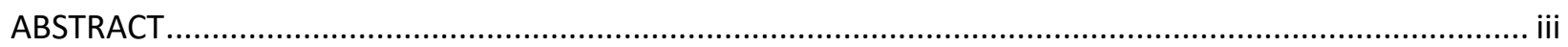

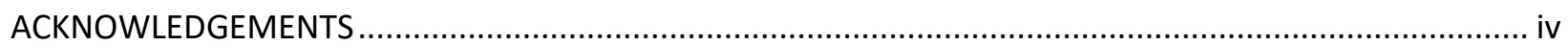

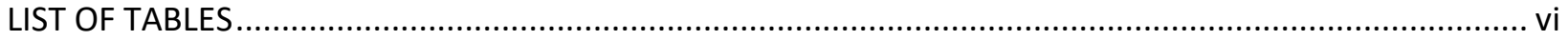

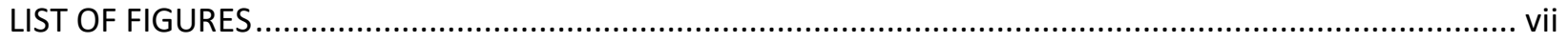

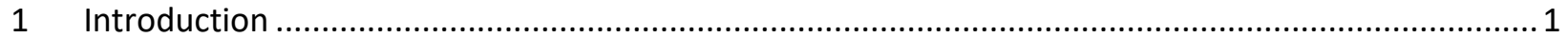

1.1 Background to Combustion Soot Research ...................................................................... 1

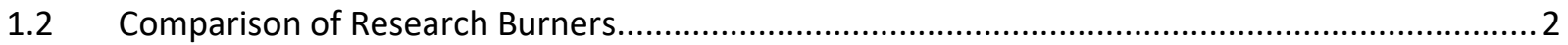

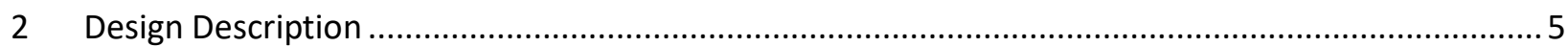

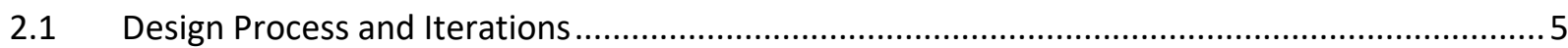

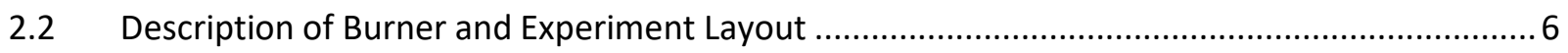

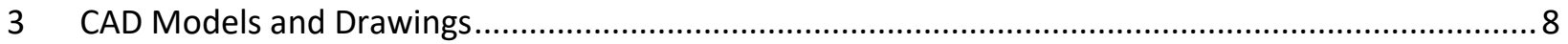

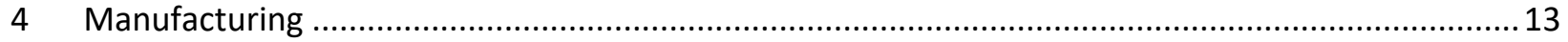

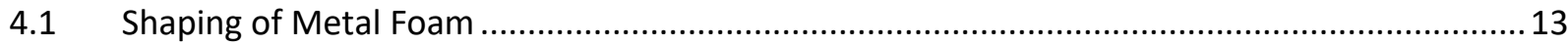

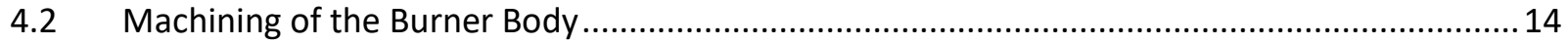

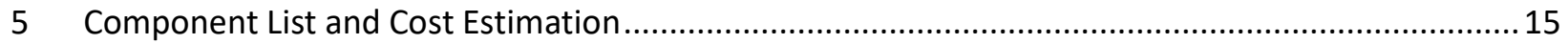

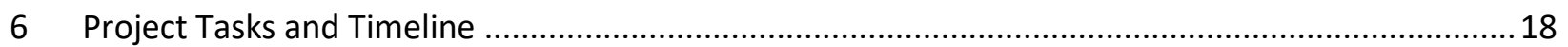

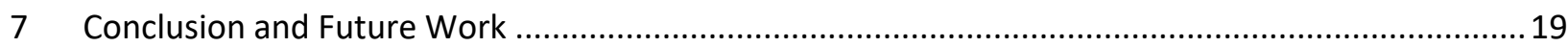

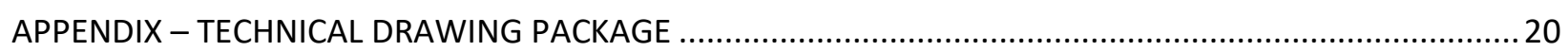

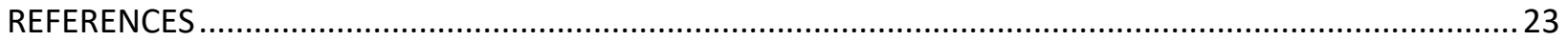




\section{LIST OF TABLES}

Table 1 Designed maximum laminar flow rate of common fuels and oxidizers....................................... 7

Table 5-1 listing of components and respective costs of the project...................................................15

Table 6-1 Gantt Chart of selected project tasks ................................................................................ 18 


\section{LIST OF FIGURES}

Figure 1-1 Soot formation and oxidization in non-premix hydrocarbon laminar flame........................... 1

Figure 2-1 Section view sketch of initial two-piece design of oxidizer tube............................................ 6

Figure 2-2 Sketch of experiment components and setup................................................................. 7

Figure 3-1 Transparent view of the assembled Catia CAD model of the co-flow burner .......................... 8

Figure 3-2 CAD model of burner with the translational stage mounted onto extruded aluminium stand.. 9

Figure 3-3 Close up of pipe clamps that will hold the burner body......................................................... 9

Figure 3-4 Cad Model of instrument table with side wing to be made from extruded aluminium ...........10

Figure 3-5 Slotted adapted to adjust height of side wing surface ....................................................... 10

Figure 3-6 Corner view of instrument table showing one of the sorbothane foot ..................................11

Figure 3-7 CAD model of the full laboratory burner set up ..................................................................12 


\section{Introduction}

Combustion of hydrocarbon fuels has been a main method of producing useful energy for numerous industries since before the industrial revolution. As the world has become more aware of the significant climate and environmental costs of burning carbon fuels, many industries have begun to shift towards alternative energy sources, but hydrocarbon fuels remain the current fuel source of choice for commercial airliners because of its high energy density and storage convenience. Research for more efficient and cleaner combustion methods remains of significant interest to the aerospace industry not only in efforts to protect the environment but also in aircraft operating cost. By studying the formation of soot, black carbon and other pollutants, combustion of carbon fuels can be made cleaner minimizing environmental impacts.

\subsection{Background to Combustion Soot Research}

Soot is normally seen as a remanence of incomplete combustion, but soot formation typically occurs throughout a flame length. Soot is initially formed in the combustion of hydrocarbons in areas of low oxygen. According to the principle combustion reaction fuel and oxygen molecules collide and form carbon dioxide and water. In fuel rich regions of the flame, collisions are less likely to involve oxygen atoms and instead bonds are formed with other more readily available carbon structures. These intermediate reactions and different kinetic mechanisms lead to the forming of polycyclic aromatic hydrocarbon (PAH) structures. Theses aromatic structures continue to grow acting as nuclei for more

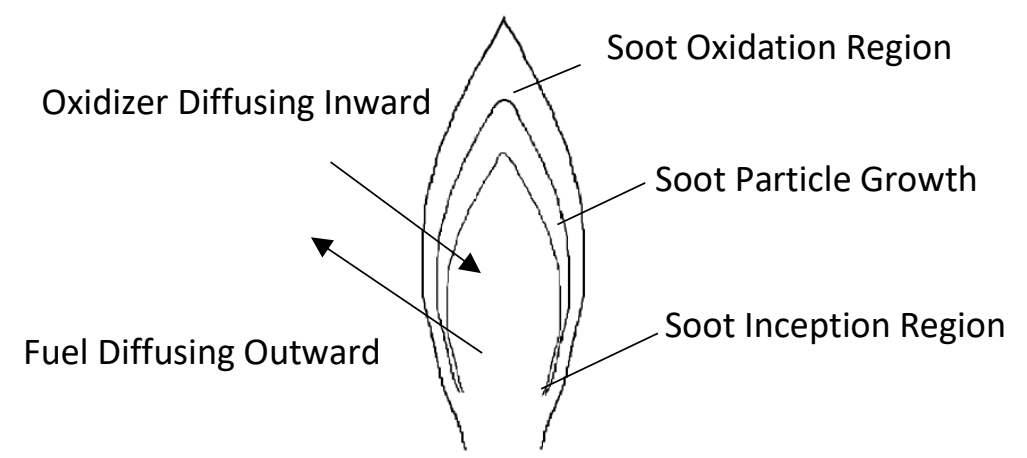

Figure 1-1 Soot formation and oxidization in non-premix hydrocarbon laminar flame

carbon structures to collect into soot particles [1]. These soot formations continue to grow and eventually break down, oxidizing according to the principle reaction as it moves to regions of the flame with more oxygen. Figure 1-1 shows the typical regions that soot forms and oxidizes. However, if the 
soot particle leaves the heated region of the flame the molecular bonds can no longer be broken without enough activation energy and the reaction cannot continue. The residual unburnt soot particles are leftover as pollutants. This is evident when a cool object is brought into the flame and becomes coated with a black layer of soot. Soot is also present when the fuel flow rate is too high, denoted by a fuel's smoke point $(\mathrm{mg} / \mathrm{s})$, when the fuel is not able to be completely combusted [2]. Characteristics of soot formations is highly dependent on the flame temperature and fuel selection [1]. Studying soot formations require steady control of a flame as the chemical kinetic mechanisms are sensitive to initial conditions [3].

\subsection{Comparison of Research Burners}

The study of combustion flames and their pollutants requires laboratory burners that can emulate controlled conditions. These conditions will alter the reaction products and pollutant concentrations predicted by the equilibrium of the chemical disassociations.

Soot formation can change due to the following flame conditions: the reaction temperature and pressure, the reaction rate and time, fuel/oxidizer flow rates and equivalence ratio, fuel and oxidizer type and physical state. Since some conditions are interdependent, i.e. an increase of oxidizer flow rate can increase the flame temperature and the reaction rate, a burner cannot separately control each factor. The burner design needs to allow for separate channels for the fuel and oxidizer, such that each flow rate can be connected to a control panel. This would also allow the opportunity to established preheated temperatures for the fuel and oxidizer. Pressure can be controlled by moving the experiment setup into a pressure chamber.

Different burner designs popular for laboratory use are available off the shelf such as Bunsen burners and its variants (eg. Tirrill, Meker, Teclu...etc.), but are more typically used as heating elements, though combustion analysis studies are possible [4]. A simple diffusion flame can also be established using a fuel jet with a single fuel line. For the purpose of the research lab, to study combustion and soot production, Bunsen burners do not provide the desired degree of precise control of fuel and air flows; and simpler non-premixed jet flames are dependent on the diffusion characteristics of the fuel with the ambient air. The oxidizers for these flames are limited to the ambient air unless experiments are contained in controlled chambers, or premixed compositions are used. 
Premixed flames refer to the combustion of fuel oxidizer blend is mixed before ignition. In non-premixed combustion the fuel and oxygen are kept separate until the ignition point where the two must first diffuse together. Non-premixed flames results in a longer reaction time and are more suited to modelling the combustion scenarios typical of aerospace propulsion designs. Non premixed combustion can be further divided into solid, liquid and gaseous fuels which differ in mixing mechanisms.

Counter flow and colinear flow burners provide better control and more suited to detailed studies. Counter flow burners arrange two opposing jets of fuel and air, resulting in a planer flame. For circular nozzles, this reduces the flame geometry to one axisymmetric dimension allowing for simplified calculations drastically reducing computational power required for associated fluid dynamic and chemical kinetic modeling. A counter flow burner is already available to the research group.

The proposed style of burner, a colinear flow (co-flow) burner, is made up of two concentric jets in the same direction. The inner jet carries the fuel and the exterior annular jet carries the selected oxidizer. The resulting flame forms between the fuel and oxidizer stream, where the gases are mixed primarily by diffusion, the fuel diffusing radially outwards and the oxidizer diffusing inwards. Thus, the reaction varies in equivalence ratio radially, being fuel rich near the center axis and oxygen rich at the outer edge. Simple mathematical models of vertical laminar flames account for the importance of radial binary diffusion and assume overall excess of oxygen [2]. It is also assumed that the jet emerges into still or coflowing oxidizer. As maintaining a still oxidizer flow field is difficult to ensure and turbulence between a fuel jet stream into still air is unavoidable, the coflowing assumption is simpler to adequately satisfy with the co-flow design.

By adjusting the flow rates the flame can be controlled for different flame heights and equivalence ratios as well as for turbulent and laminar flames. Roper's experimental correlations for lean combustion provides one method of predicting the flame height can be predicted using, given as [5]:

$$
L_{e x}=1330 \frac{Q_{f}\left(T_{\infty} / T_{f}\right)}{\ln \left(1+\frac{1}{S}\right)}
$$

Where $Q_{f}$ is the volumetric flow rate, $T_{\infty}, T_{f}$ are the flame and fuel temperature respectively and $\mathrm{S}$ is the stochiometric fuel-oxidizer ratio. 
Inverted burners are similar to co-flow burners, but as the fuel and air jets are directed downwards to alter the effects of buoyancy, reducing flickering of the flame [6]. Inverted burners are commercially available for the purpose of soot generation [7].

Inverse burners share the co-flow arrangement of concentric tubes supplying the fuel and oxidizer, but the central jet delivers the oxidizer and the outer jet delivers the fuel. This style of flame has low NOx emissions and soot luminosity, but the flame is less stable [8]. 


\section{Design Description}

The purpose of the burner is to create a stable hydrocarbon combustion flame such that the flame characteristics and soot measurement can be determined with confidence and accuracy. The burner should be capable of producing a laminar non-premixed flame. The flow rates of the burner will be controlled by a separately designed control panel. Soot detection will be conducted using a line of sight attenuation method. This style of soot detection works by projecting a controlled light source through the burner flame. Opaque soot particle can then be detected by noting differences in light intensities as described in [9]. The design will include supporting structures to mount soot sampling equipment including an CMOS camera and LED Light source on opposing sides of the burner. In order to reduce the project costs, custom machined parts would only be available to the burner body, all other supporting components were to be restricted to readymade products from various laboratory equipment suppliers.

\subsection{Design Process and Iterations}

The design process began with familiarization research of co-flow burners and the sourcing of metal foams and translational stages. Following discussions, the research group requested the burner have a fuel tube about half inch and an oxidizer diameter between two to three inches. Literature review of coflow burners dimensions used in published combustion soot research supported similar dimensions inclined towards the three inch scale [10], [11], [12]. The final sizing of the burner would also be restricted to available mounting hardware in order to avoid the need to create a custom solution. Initial designs of the oxidizer chamber were based on a two-piece model with a pipe stock with and threaded end cap fitting (see Figure 2-1). After further assessment of the manufacturing considerations, the burner was redesigned with the oxidizer chamber as a single tube. Design iterations of the supporting burner stand and instrument table, were heavily dependent on the available off the shelf components that could be sourced effectively and progressed by assembling of a CAD models to ensure compatibility. 


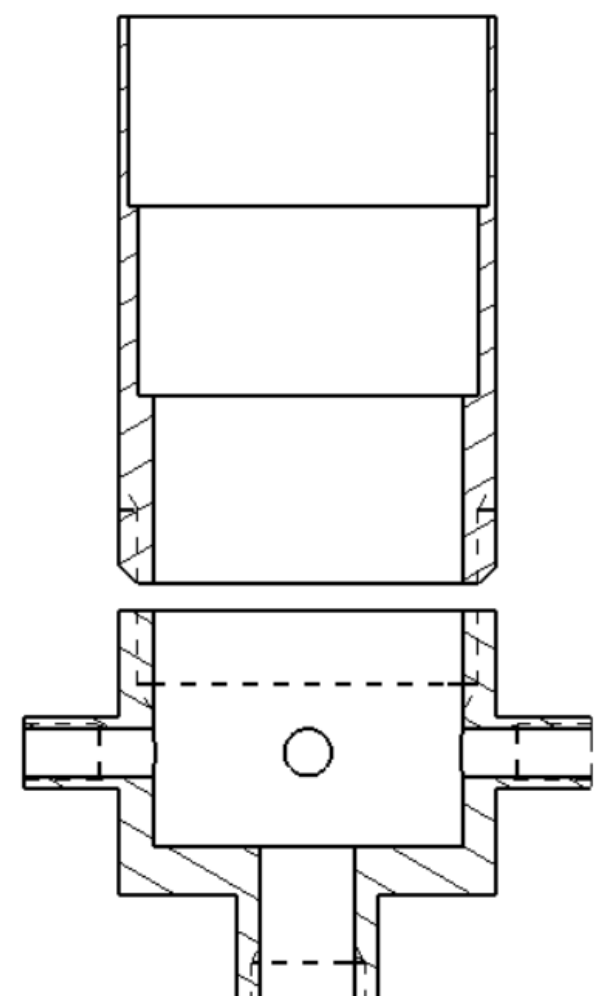

Figure 2-1 Section view sketch of initial two-piece

\subsection{Description of Burner and Experiment Layout}

The burner body consists of an inner fuel tube and an external oxidizer tube with a closed bottom. The top edge of the fuel pipe is chamfered from the outside to reduce disturbances to the flow, improving the stability of the flame [10]. The fuel tube passes through the bottom of the outer tube using Swagelok bore through adapter. The oxidizer flow is stabilized with a layer of glass beads between two layers of porous metal foam in order to break up eddies and irregular motions from the oxidizer inlets to help achieve consistent vertical laminar flow. The oxidizer enters the outer tube through three inlet ports with Swagelok adapters. Preference for three inlets rather than four allows for the use of readily available four-way adapter in the oxidizer inlet line.

As the research group intends to use a line of sight attenuation soot detection method, where the flame is placed between the detection camera and light source. The burner body will be mounted onto a computer controlled vertical translational stage. The translational stage allows the flame to be moved across the camera's viewing angle, rather than to pan the camera across the flame length. This would 
prevent the need to recalibrate the sensitive soot detecting camera equipment following each panning movement (see Figure 2-2).

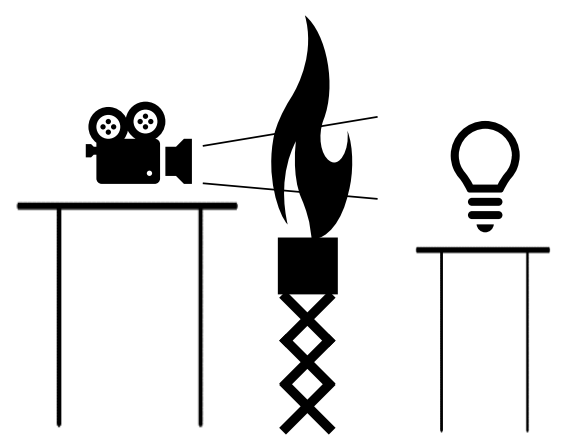

Figure 2-2 Sketch of experiment components and setup

The burner staging will be arranged onto a small stand between a larger instrument table and its side wing on which the sensor camera and light will be placed. Although the experiment set up is not foreseen to be frequently moved other than into a pressure chamber, both the table and burner stand will have removable casters mounted on one end for convivence when necessary. The table and burner stand will be constructed out of extruded aluminum.

For critical Reynolds number of 2300 for duct flow, Table 1 shows the estimated maximum flow rates at which the proposed burner design will maintain a laminar flow. These were calculated based on gaseous physical properties expected at ambient conditions $\left(20^{\circ} \mathrm{C}\right.$ and $\left.1 \mathrm{~atm}\right)$. The flow rates of the oxidizers were estimated using a hydraulic diameter calculated as $D_{h}=2\left(r_{o}-r_{i}\right)$.

Table 1 Designed maximum laminar flow rate of common fuels and oxidizers

\begin{tabular}{ccccc} 
Gas & $\begin{array}{c}\text { Density }\left(\mathrm{kg} / \mathrm{m}^{3}\right) \\
{[11]}\end{array}$ & $\begin{array}{c}\text { Viscosity } \\
\left(10^{-5} \mathrm{~Pa} \mathrm{~s}\right)[12]\end{array}$ & Velocity $(\mathrm{m} / \mathrm{s})$ & $\begin{array}{c}\text { Volumetric Flow } \\
\text { Rate }(\mathrm{L} / \mathrm{s})\end{array}$ \\
\hline Methane $\left(\mathrm{CH}_{4}\right)$ & 0.668 & 1.10 & 2.982 & 0.279 \\
\hline Ethane $\left(\mathrm{C}_{2} \mathrm{H}_{6}\right)$ & 1.24 & 0.921 & 1.345 & 0.126 \\
\hline Propane $\left(\mathrm{C}_{\mathbf{3}} \mathrm{H}_{\mathbf{8}}\right)$ & 1.898 & 0.802 & 0.765 & 0.072 \\
\hline Butane $\left(\mathrm{C}_{4} \mathrm{H}_{10}\right)$ & 2.5 & 0.728 & 0.527 & 0.049 \\
\hline Ethylene $\left(\mathrm{C}_{2} \mathrm{H}_{4}\right)$ & 1.157 & 1.03 & 1.612 & 0.151 \\
\hline Air & 1.205 & 1.73 & 1.155 & 1.400 \\
\hline Oxygen $\left(\mathrm{O}_{2}\right)$ & 1.331 & 2.04 & 1.233 & 1.495 \\
\hline
\end{tabular}




\section{CAD Models and Drawings}

CatiaV5 was used to draw the proposed design and to layout the off the shelf part to ensure that the components would fit together as intended. Figure 3-1 shows the assembled burner whose components are to be machined. The components are the oxidizer chamber, two metal foam inserts, coupling adapters and the fuel pipe.

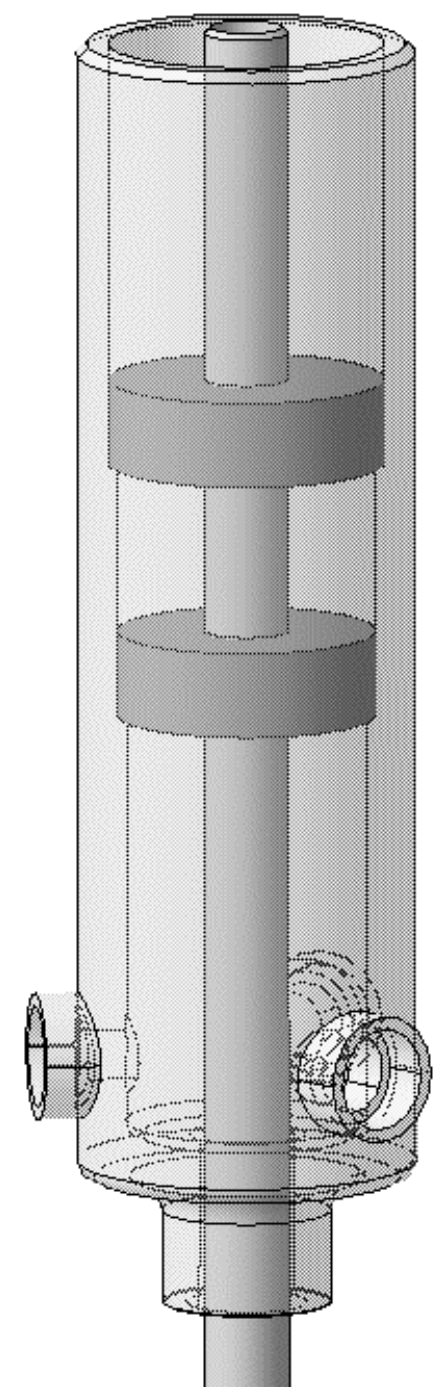

Figure 3-1 Transparent view of the assembled Catia CAD model of the co-flow burner 
Figure 3-2 shows the burner mounted onto the translational stage and stand. The translational stage was selected based on its available range of motion $(50 \mathrm{~cm})$, accuracy $( \pm 0.02 \mathrm{~mm})$ and cost. The translational stage required numerous adapters to assemble with the burner and the stand due to its limited mounting holes and the desired movement direction. The proposed design is made entirely of off the shelf parts requiring one modification; to re-drill and tap a M4 hole to M6 on each of the burner holders as shown in the center of Figure 3-3 on the inner wall of the clamp.

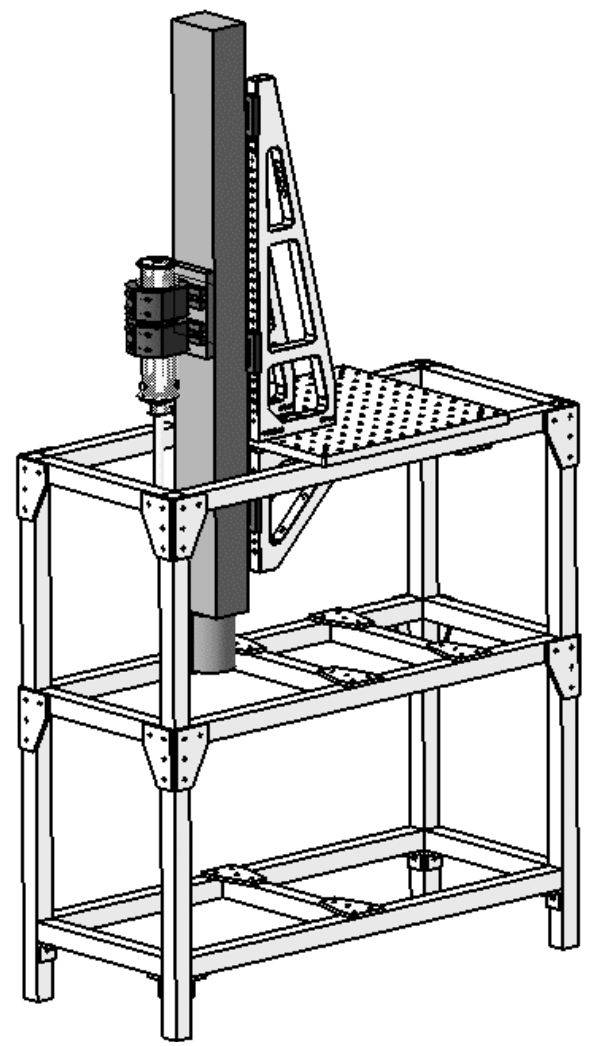

Figure 3-2 CAD model of burner with the translational stage mounted onto extruded aluminium stand

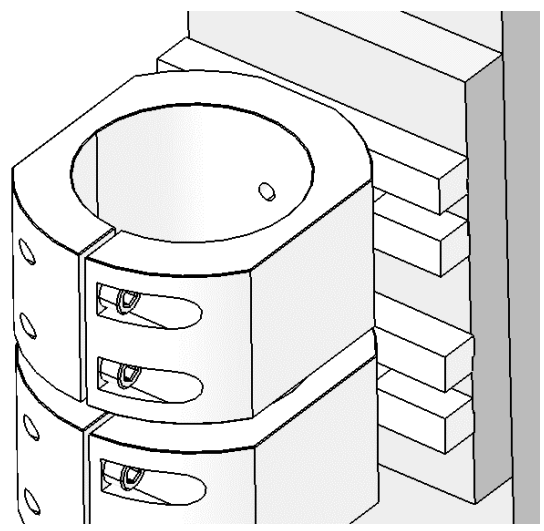

Figure 3-3 Close up of pipe clamps that will hold the burner body 
The instrument table shown in Figure 3-4 features a vibration damping tabletop and a side wing extension to hold the soot detection camera and light source on either side of the flame. The damping tabletop weighs $54 \mathrm{~kg}$ and required a larger 1.5 inch aluminum extrusion product line, while the burner stand was designed using 1 inch aluminium extrusions.

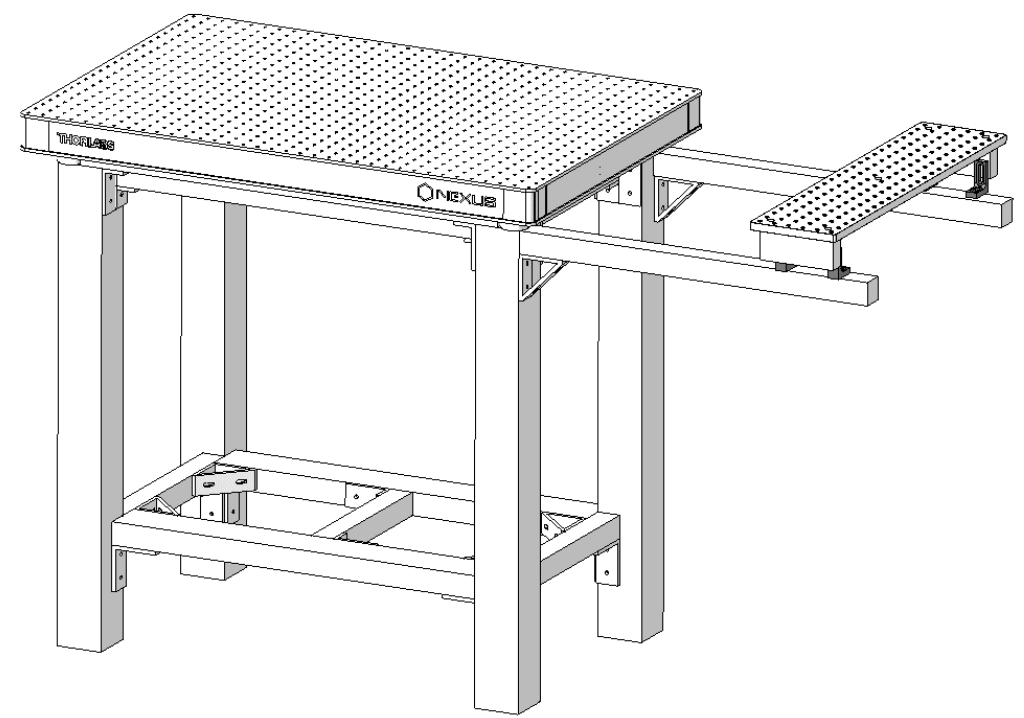

Figure 3-4 Cad Model of instrument table with side wing to be made from extruded aluminium

As the working surfaces of the table and side wing were requested to be the same height, slotted adapters were needed to accommodate the thicker vibration damping table as shown in Figure 3-5.

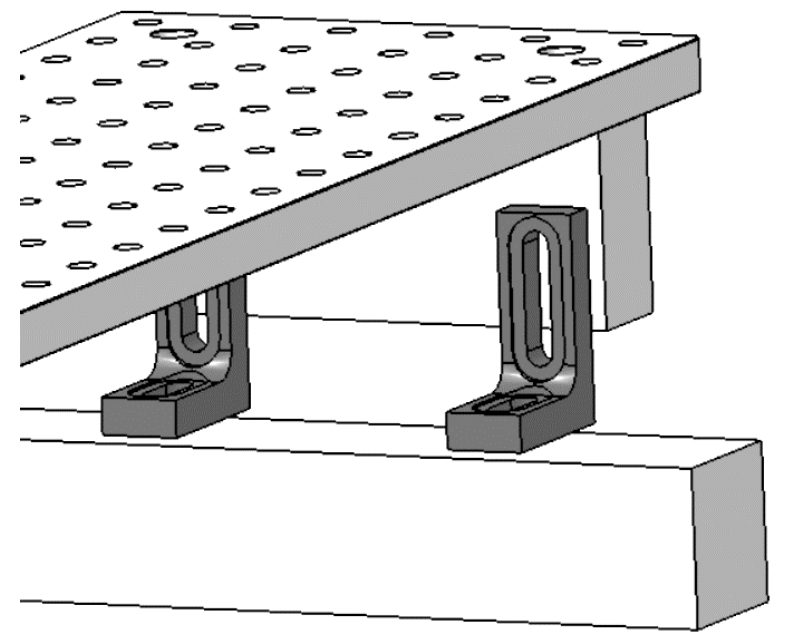

Figure 3-5 Slotted adapted to adjust height of side wing surface 
The damping tabletop is mounted onto sorbothane feet rated for 50lbs each to further reduce unwanted vibrations. In order to avoid screwing the tabletop to the frame, as this would reduce the effectiveness of the sorbothane feet, the tabletop sits freely on the frame. Horizontal motion is restricted by the $3 / 4$ inch extrusions, keeping the table from sliding off the frame shown in Figure 3-6.

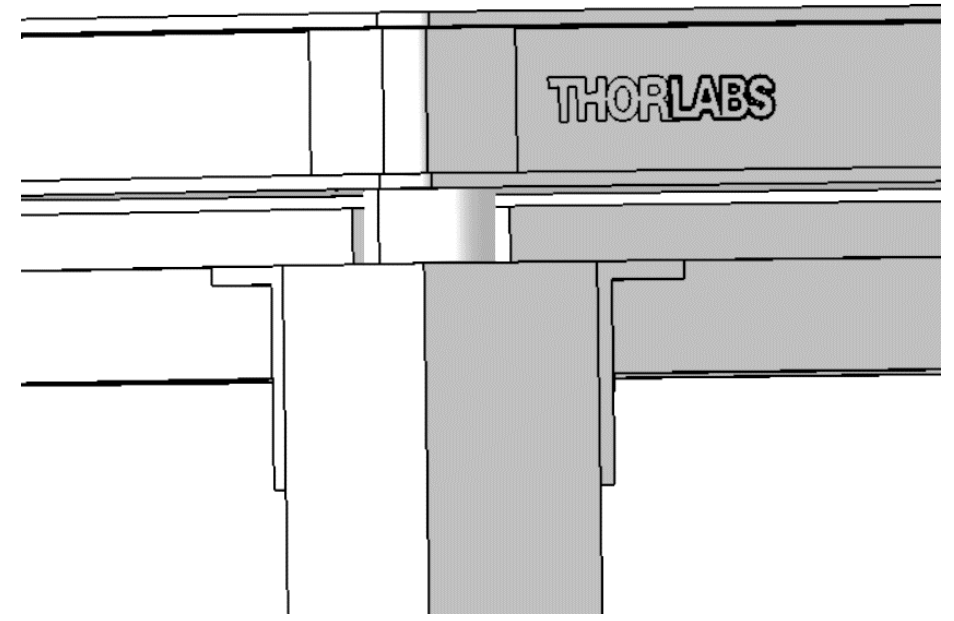

Figure 3-6 Corner view of instrument table showing one of the sorbothane foot

The components together would be laid out as shown in Figure 3-7. Considerations were made for the side table to be mounted on hinges to allow the burner stand to easily be moved out from between the instrument table and extension. However, the sensitivity of the instruments to be used on surface cannot yet be determined leaving the hinges aside for future modifications. The side wing surface currently must be removed for the burner stand to come out. The casters for the table and stand are not shown in these drawings. 


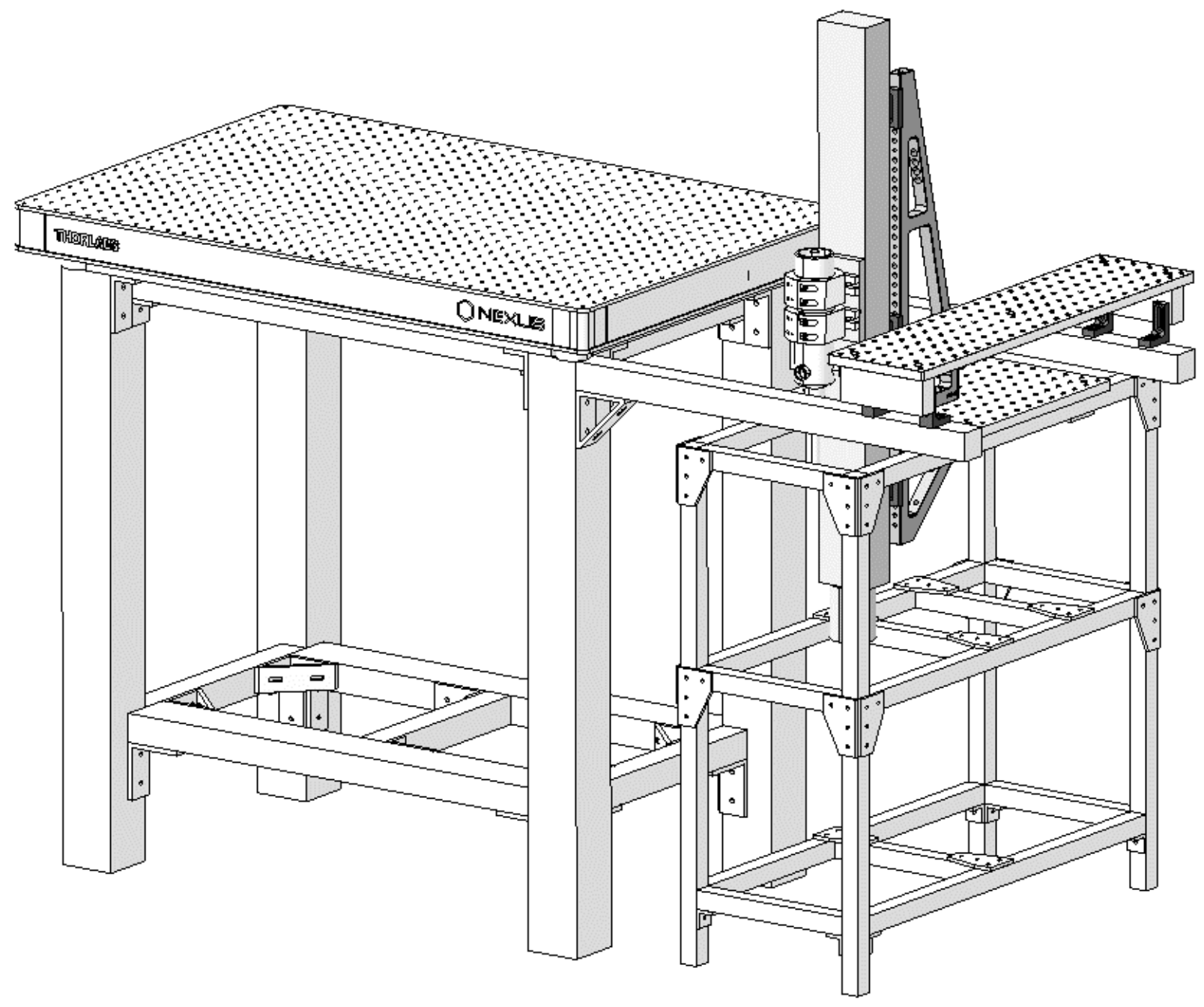

Figure 3-7 CAD model of the full laboratory burner set up 


\section{Manufacturing}

Two main manufacturing considerations were required for the design of the co-flow burner. The shaping of the metal foam and the machining of the burner body. The design of the burner stand and instrument table consisted of retail components that would only require manual assembly with few minor modifications. The aluminum extrusions would be purchased cut to length by the supplier.

\subsection{Shaping of Metal Foam}

The use of metal foam and glass beads were chosen to be used to help stabilize the flow. Due to initial difficulty in sourcing metal foam with the desired porosity and cell density, alternatives such as metal mesh, carbon foam were also investigated, however these were not found to be as practical. Metal mesh was only available in thin sheets and carbon foam was concluded to be too fragile.

The use of porous metal foam (or open cell foam) creates potential difficulties in the machine process. Machining of metal foam tends to be difficult because the structure of the foam consists of nodes and thin branches of metal, such that each edge presented along the cutting surface will form micro burrs. Depending on the hardness of the material and the cutting conditions, conventional machining of the material will have a tendency to either bend over and clog the pore or fracture at a depth below the desired dimensions.

Wire electrical discharge machining (EDM) is a potential alternative as shearing is no longer the cutting mechanism and the tool does not physically touch the component. EDM works by moving an electrode tool along the cutting path where electrical sparks are used to erode the work piece. However, this method of machining was deemed too expensive and beyond the budget of this project. Similarly, casting the component to dimension would not be feasible.

A more convenient method of using ice as an infiltrate to support the material during conventional machining as suggested in a study showing reduction of smearing while machining metal foam [13]. The study showed reduced smearing of the pores with both ice and wax. The use of wax as medium would be preferred for easy of handling as it would remain solid at room temperature. This method would first submerge the metal foam blank in liquid wax. The wax filled metal foam blank is allowed to cool and wax solidified before being machined, after which the wax can be melted and drained from the work piece. This method would only be considered if other techniques were not accessible as limited smearing of the pore would still be present.

Depending on the capability of the manufacturer, laser CNC cutting techniques can also be applied. A study was found on the feasibility of laser cutting done with nickel metal foam with 90 pore per inch 
[14]. The study found that laser cutting method produced good cuts with little to no distortion to the pore structure, however the cutting speed had to be carefully selected to control material oxidation and kerf width. Laser cutting was the method was suggested by the supplier, who had the facilities to laser cut the material. Being that the supplier was accustomed to their own equipment settings that worked best for their product, the machining was ordered with metal foam purchased rather than to have the metal foam machined with the burner body.

\subsection{Machining of the Burner Body}

The design of the burner body was one of two approaches. The chosen design has the exterior oxidizer chamber machined from one piece of aluminum. In initial design iterations (as shown in Figure 2-1), the burner oxidizer chamber was designed as a two-piece, pipe/tube stock with and threaded end cap fitting. This was thought to reduce the manufacturing cost as less material would need to be removed, however this was abandoned due to the additional machining steps and the difficulty in sourcing a nominal pipe with walls thick enough to accommodate the offsets needed to hold the metal foam inserts. Attempts were made to move the oxidizer inlets to the bottom face in order create more direct flow into the oxidizer chamber, but the chosen oxidizer chamber diameter was too small. Additional information of the machined components can be seen in the APPENDIX - TECHNICAL DRAWING PACKAGE. 


\section{Component List and Cost Estimation}

The project included numerous off the shelf components, two suppliers where majority of the components were sourced were Thorlabs Inc. for adapters and mounts, as well as Faztek-DR Design Inc. for aluminum extrusion and hardware. Table 5-1 shows the components of the design and their expected cost. The total project cost is estimated to cost seven thousand seven hundred dollars. This estimate excludes shipping, handling fees and taxes.

Table 5-1 listing of components and respective costs of the project

\begin{tabular}{|c|c|c|c|}
\hline Component & Qty. & $\begin{array}{l}\text { Cost Est } \\
\text { (Cad \$) }\end{array}$ & Supplier Description and Notes \\
\hline Burner & & & $\$ 2224.31$ \\
\hline Oxygen Nipple & 3 & 10.20 & SS-400-1-4 1/4 in. Tube OD x 1/4 in. Male NPT \\
\hline Fuel Pipe Adapter & 1 & 28.17 & $\begin{array}{l}\text { Stainless Steel Swagelok Tube Fitting, Bored-Through Male Connector, } \\
1 / 2 \text { in. Tube OD x } 1 / 2 \text { in. Male NPT }\end{array}$ \\
\hline Metal Foam Blank & 1 & 432.18 & Recemat BV - Retimet 80 \\
\hline $\begin{array}{l}\text { Machining of } \\
\text { Metal foam }\end{array}$ & 1 & 476.13 & Recemat BV \\
\hline $\begin{array}{l}\text { Other Machined } \\
\text { Parts }\end{array}$ & 1 & 1187.20 & GTA Machining Solutions \\
\hline
\end{tabular}

\begin{tabular}{|c|c|c|c|}
\hline Burner Stand & & & $\$ 3180.05$ \\
\hline Breadboard & 1 & 155.53 & $\begin{array}{l}\text { MB3030/M - Aluminum Breadboard, } 300 \mathrm{~mm} \times 300 \mathrm{~mm} \times 12.7 \mathrm{~mm}, \mathrm{M} 6 \\
\text { Taps }\end{array}$ \\
\hline $18 "$ brackets & 2 & 133.10 & VB01B/M - 18" Vertical Bracket for Breadboards, M6 Holes \\
\hline 6" bracket & 2 & 77.37 & VB01A/M - 6" Vertical Bracket for Breadboards, M6 Hole \\
\hline Slotted base & 3 & 27.58 & BA2L/M - Tapped Mounting Base, $50 \mathrm{~mm} \times 100 \mathrm{~mm} \times 9.5 \mathrm{~mm}$, Metric \\
\hline Stage adapter & 2 & 5.77 & BA1/M - Mounting Base, $25 \mathrm{~mm} \times 75 \mathrm{~mm} \times 10 \mathrm{~mm}$ \\
\hline Pipe clamp & 2 & 40.86 & $\begin{array}{l}\text { C2RC/M - Slip Ring for } \varnothing 2 " \text { ( } \varnothing 50.8 \mathrm{~mm} \text { ) Components, } \\
\text { M4 Tap mounting hole to be redrilled to } \mathrm{m} 6\end{array}$ \\
\hline Translational Stage & 1 & $2,070.00$ & EZS6-E050-AZMKD, Linear Slide with AZ series Absolute Encoder Motor \\
\hline $\begin{array}{l}\text { 1" Aluminum } \\
\text { Extrusion - 9" }\end{array}$ & 10 & 2.75 & 10QE1010 - 1" x 1" Smooth T-Slotted Aluminum Extrusion \\
\hline 24" - 20 - & 6 & 6.50 & \\
\hline$-\quad 27^{\prime \prime}$ & 4 & 7.25 & \\
\hline $\begin{array}{l}\text { - Corner } \\
\text { plate }\end{array}$ & 16 & 8.58 & 10JP4203 - 10 Series 4 Hole $90^{\circ}$ Joining Plate w/screws and nuts \\
\hline Corner Bracket & 8 & 4.73 & $\begin{array}{l}\text { 10CB4100 - } 10 \text { SERIES } 2 \text { HOLE INSIDE CORNER BRACKET w/screws and } \\
\text { nuts }\end{array}$ \\
\hline T-plate & 8 & 9.45 & 10JP4207 - 10 Series 4 Hole Tee Joining Plate w/screws and nuts \\
\hline End Caps & 8 & 1.55 & 10AC7630 10 Series - Black Plastic End Caps w/screw \\
\hline Small handle & 2 & 5.25 & $\begin{array}{l}\text { 13AC7300 - } 10 \text { Series Black Plastic Handle w/mounting hardware } \\
\text { (SMALL) }\end{array}$ \\
\hline
\end{tabular}




\begin{tabular}{|c|c|c|c|}
\hline M5 w/washers & 4 & & \\
\hline M6 $\times 1.0 \times 25 \mathrm{~mm}$ & 23 & 13.22 & $\begin{array}{l}\text { Zinc-Plated Alloy Steel Socket Head Screw, M6 x } 1 \text { mm Thread, } 25 \text { mm } \\
\text { Long }\end{array}$ \\
\hline M6 x1.0 & 6 & 13.13 & X-Dr 10pcs 1mm Pitch M6 x 70mm Partially Threaded Socket Head \\
\hline 10 series T-nut & 12 & & \\
\hline 15 series T-nut & 4 & & \\
\hline Component & Qty. & $\begin{array}{l}\text { Cost Est } \\
\text { (Cad \$) }\end{array}$ & Supplier Description and Notes \\
\hline Instrument Table & & & $\$ 2328.51$ \\
\hline Large breadboard & 1 & $1,208.73$ & $\begin{array}{l}\text { B6090A - Nexus Breadboard, } 600 \mathrm{~mm} \times 900 \mathrm{~mm} \times 60 \mathrm{~mm}, \mathrm{M} 6 \mathrm{x} \\
\text { 1.0 Mounting Hole }\end{array}$ \\
\hline $\begin{array}{l}\text { Side wing } \\
\text { breadboard }\end{array}$ & 1 & 162.32 & $\begin{array}{l}\text { MB1560/M - Aluminum Breadboard, } 150 \text { mm x } 600 \text { mm x } 12.7 \\
\text { mm, M6 Taps }\end{array}$ \\
\hline Damping feet & 1 & 33.28 & $\begin{array}{l}\text { AV6/M - } \varnothing 45.0 \text { mm Sorbothane Feet, Internal M6 Mounting } \\
\text { Thread, } 4 \text { Pieces }\end{array}$ \\
\hline $\begin{array}{l}\text { wing height } \\
\text { extension }\end{array}$ & 4 & 27.85 & AB90H - Slim Right-Angle Bracket with Counterbored Slots \\
\hline 1.5" extruded Al & & & \\
\hline 3"x3" & $\begin{array}{l}31.15^{\prime \prime} \\
\times 4\end{array}$ & 49.75 & $\begin{array}{l}\text { 15QE3030L - 3.0" x 3.0" Lite Smooth T-Slotted Aluminum } \\
\text { Extrusion }\end{array}$ \\
\hline $1.5 \times 3$ & $\begin{array}{l}25.74^{\prime \prime} \\
\times 2\end{array}$ & 25.88 & $\begin{array}{l}\text { 15QE1530L - 1.5" x 3" Light Smooth T-Slotted Aluminum } \\
\text { Extrusion }\end{array}$ \\
\hline $1.5 \times 1.5$ & $\begin{array}{l}25.74 " \\
x 2\end{array}$ & 14.63 & $\begin{array}{l}\text { 15QE1515UL - 1.5" X 1.5" ULTRA-LIGHT SMOOTH T-SLOTTED } \\
\text { ALUMINUM EXTRUSION }\end{array}$ \\
\hline $1.5 \times 1.5$ & $\begin{array}{l}13.929 " \\
x 4\end{array}$ & 10.24 & \\
\hline $1.5 \times 1.5$ & $\begin{array}{l}10.929 " \\
x 1\end{array}$ & 7.31 & \\
\hline $1.5 \times 1.5$ & $24 " \times 2$ & 14.14 & \\
\hline $1.5 x .75$ & $\begin{array}{l}28.74 " \\
x 2\end{array}$ & 12.24 & 15QE1575 - 1.5" x 0.75" Smooth T-Slotted Aluminum Extrusion \\
\hline $1.5 x .75$ & $\begin{array}{l}16.929 " \\
x 2\end{array}$ & 8.04 & 15QE1575 - 1.5" x 0.75" Smooth T-Slotted Aluminum Extrusion \\
\hline $\begin{array}{l}\text { 1"x2" extruded } \\
\text { AL }\end{array}$ & $5^{\prime \prime} \times 2$ & 4.94 & 10QE1020 - 1" x 2" Smooth T-Slotted Aluminum Extrusion \\
\hline $\begin{array}{l}3 \text { hole corner } \\
\text { bracket }\end{array}$ & 10 & 7.28 & $\begin{array}{l}15 C B 4802-15 \text { Series } 3 \text { Hole Inside Corner Bracket w/screws and } \\
\text { nuts }\end{array}$ \\
\hline $\begin{array}{l}2 \text { hole corner } \\
\text { bracket }\end{array}$ & 8 & 5.09 & $\begin{array}{l}\text { 15CB4801 - } 15 \text { Series } 2 \text { Hole Inside Corner Bracket w/screws and } \\
\text { nuts }\end{array}$ \\
\hline corner gusset & 10 & 10.61 & 15CB4842 - 15 Series 4 Hole Inside Corner Gusset \\
\hline $\begin{array}{l}4 \text { hole corner } \\
\text { bracket }\end{array}$ & 8 & 8.18 & 15CB4804 - 15 Series 4 Hole Inside Corner Bracket \\
\hline End cap $3 \times 3$ & 4 & 3.48 & 15AC7832 - 3" x 3" Black Plastic End Cap w/screws \\
\hline
\end{tabular}


15AC7825-SS - 1.5" x 1.5" Black Plastic End Cap w/stainless

\begin{tabular}{llll} 
End cap 1.5x1.5 & 2 & 1.85 & screw \\
\hline Handle & 2 & 8.57 & $\begin{array}{l}\text { 13AC7301 - 15 Series Black Plastic Handle w/mounting hardware } \\
\text { (MEDIUM) }\end{array}$ \\
\hline Casters & 1 & 85.95 & $\begin{array}{l}\text { POWERTEC 17001 Workbench Caster Kit with Multi-Mounting } \\
\text { Options, Pack of 4 - pair for burner stand }\end{array}$ \\
\hline
\end{tabular}




\section{Project Tasks and Timeline}

Table 6-1 show a Gantt chart of selected project tasks and achievements. The project was initiated as a two-semester project, but the student was later advised to aim for completion within the semester. The instrument table required significant redesign following errors in recording its expected weight.

Table 6-1 Gantt Chart of selected project tasks

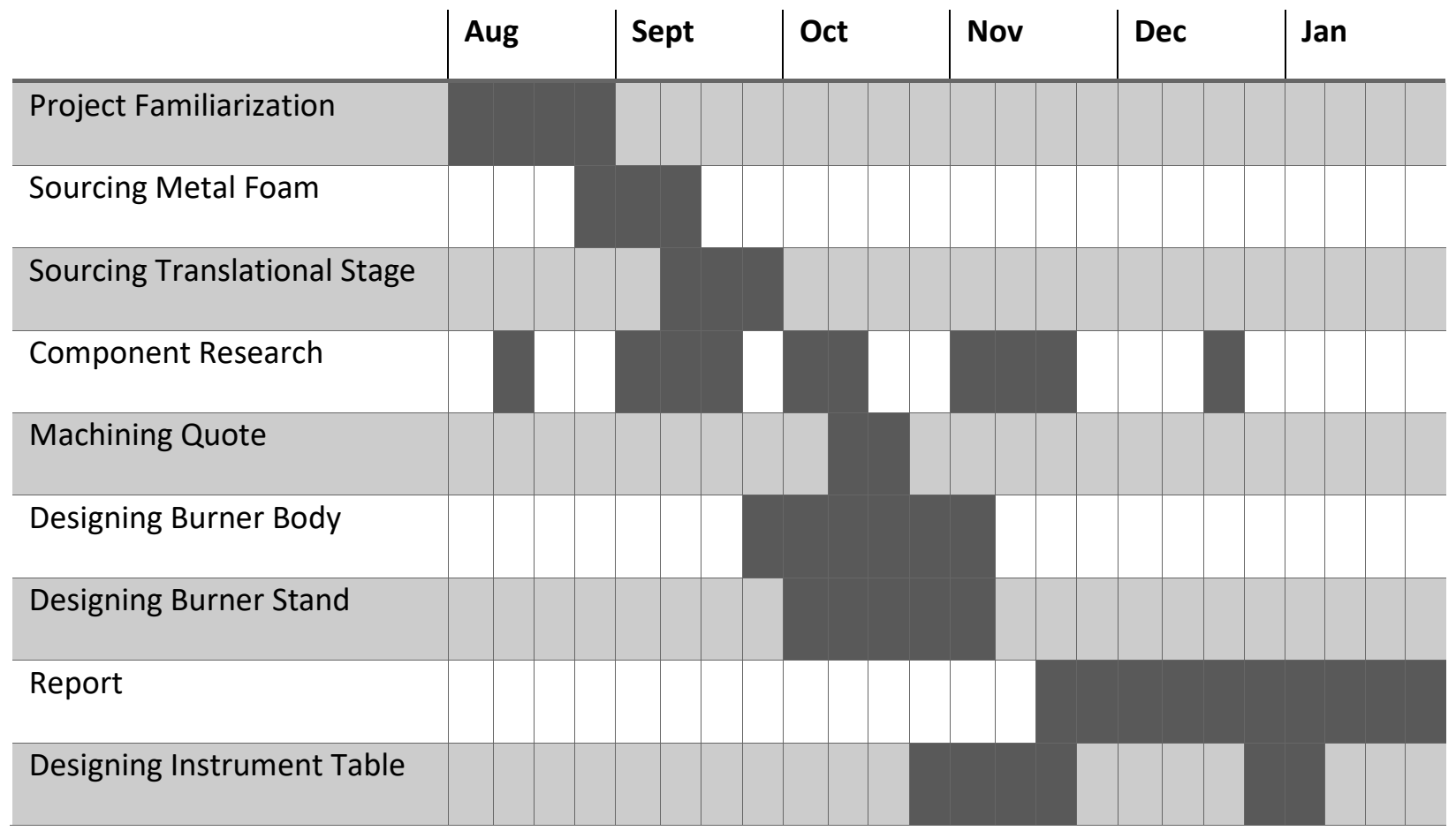




\section{Conclusion and Future Work}

In summary, the proposed burner will be used in combustion soot research. The burner needs to provide a laminar non-premixed flame. The burner will use of a set of porous metal foam inserts and glass beads to reduce swirling and turbulence within the oxidizer chamber. Maximum laminar flow rates for common fuel and oxidizers were estimated based on Reynolds number of 2300 . The proposed burner design was presented along with the designs for the supporting burner stand with a translational stage, as well as the vibration damping instrument table with a side extension. The sourced components were fully listed, and the project cost estimations were given.

Additional work is needed to prepare the burner for laboratory operation. After the assembly of the proposed design and initial testing, a control panel should be designed and built. As the co-flow burner design has separate chambers for the fuel and oxidizer, a control panel should be designed to monitor and control the fuel and oxidizer flow rates entering the burner from a computer, as well as implement an initial temperature to the combustion reactants. Together with the control panel, the proposed burner design allows for separate control of the fuel and oxidizer conditions of a diffusion flame. The burner arrangement also considers the possibility of operating in a pressure chamber in order to simulate different elevations. The opportunity to control and manipulate these factors opens up a larger range of experimental studies that can be conducted with this burner.

Creating a custom CFD model with thermodynamic and chemical considerations of the burner at this stage can potentially be useful for comparing the expected theoretical results to the performance of the burner and control panel system. This would allow the user to detect system inefficiencies and inaccuracies and make appropriate changes to fine tune the physical burner system the control panel or the CFD model. 
APPENDIX - TECHNICAL DRAWING PACKAGE

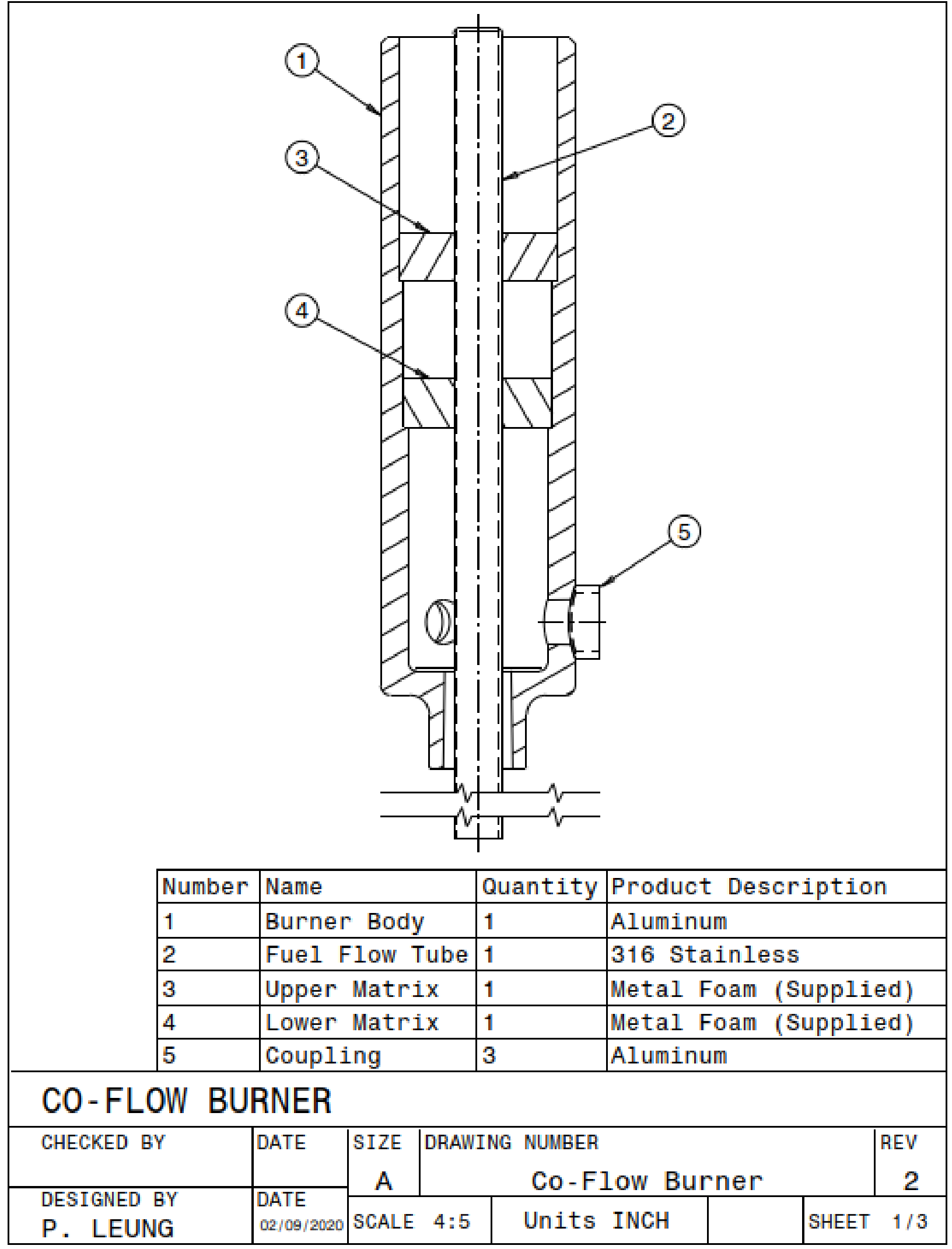




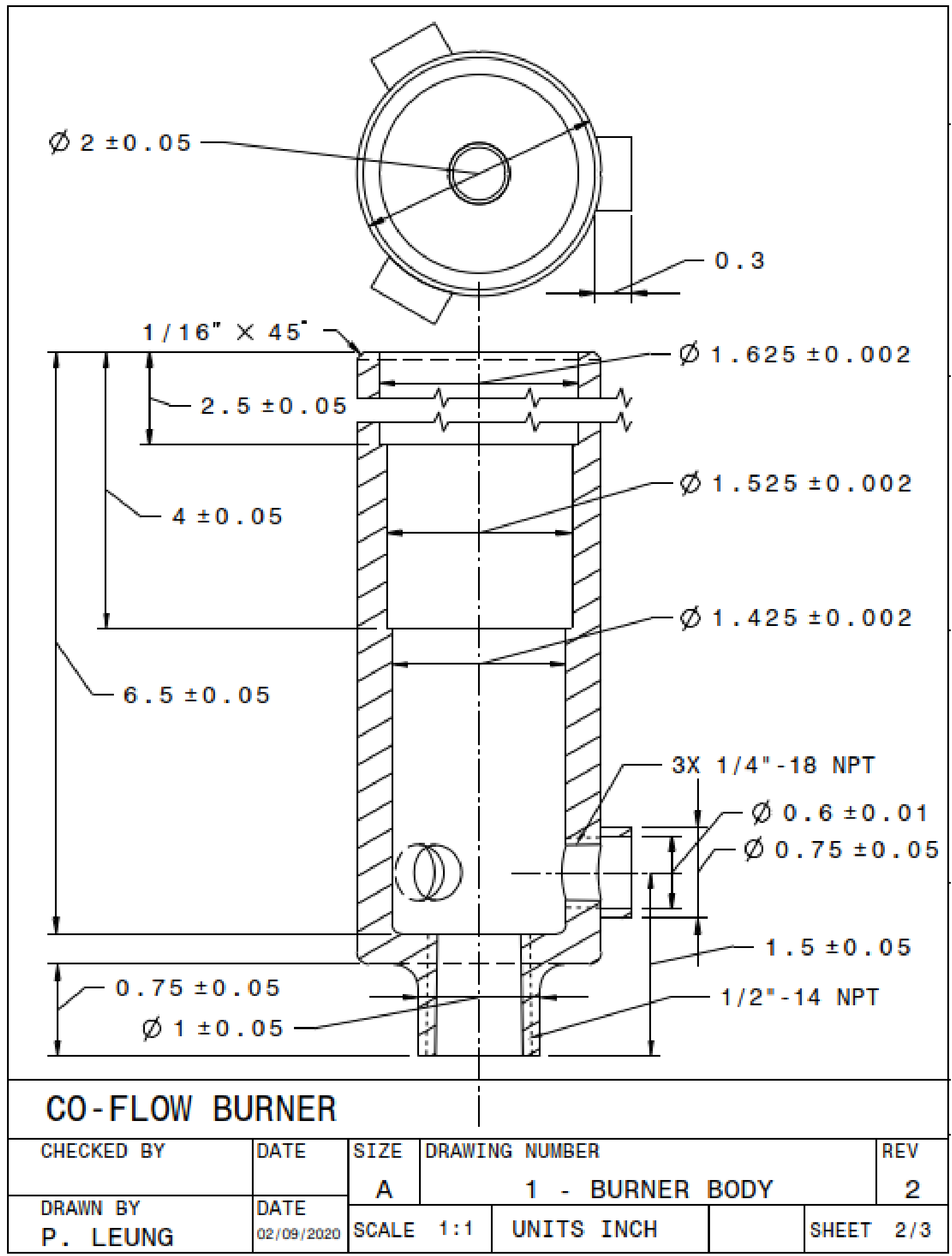




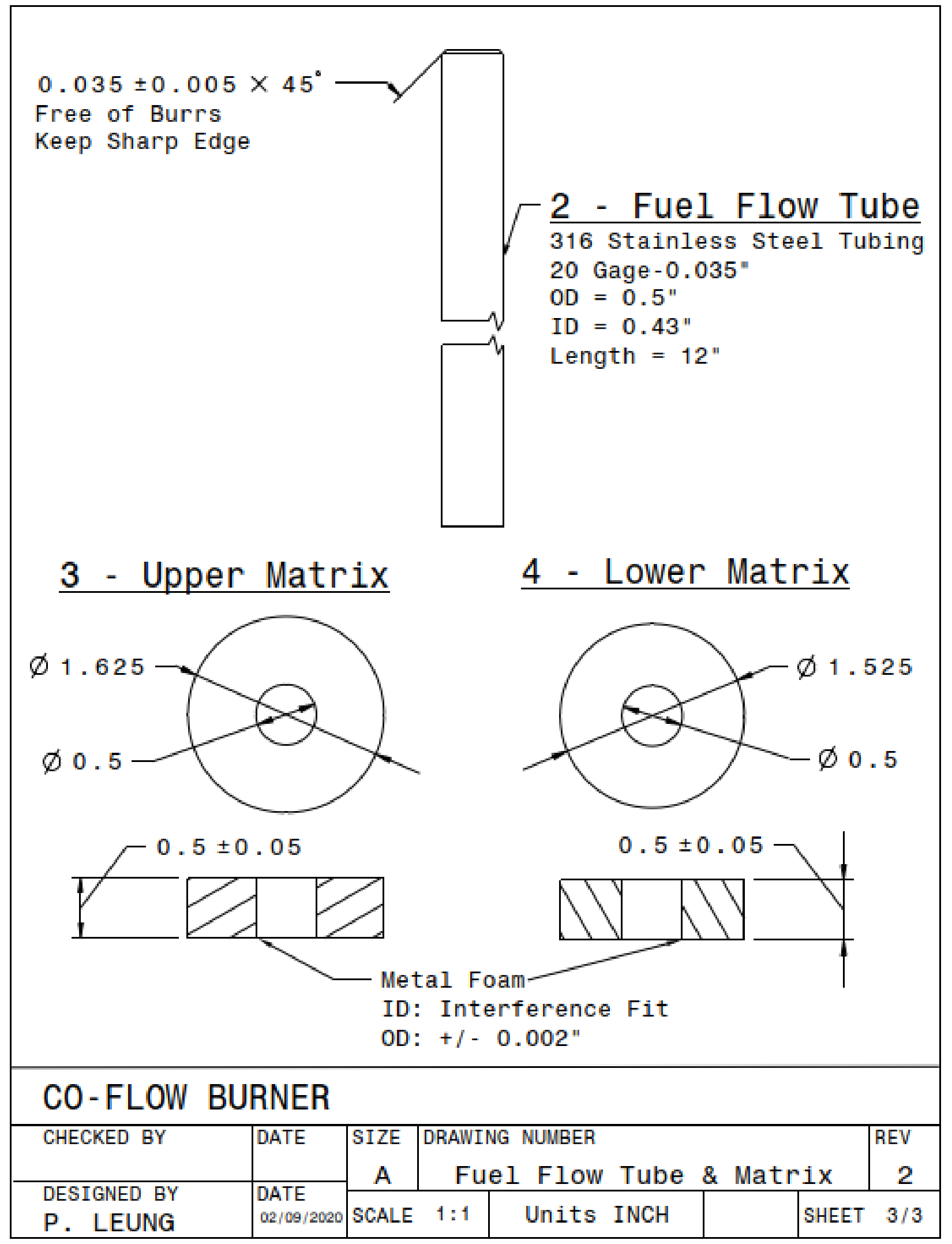




\section{REFERENCES}

[1] I. Glassman, "Soot Formation in Combustion Processes," Symposium (International) on Combustion, vol. 22, no. 1, pp. 295-311, January 1989.

[2] S. R. Turns, An Introduction to Combustion Concepts and Applications, Third ed., New York: McGraw-Hill, 2012, pp. 311-361.

[3] H. J. Curran, "Developing detailed chemical kinetic mechanisms for fuel combustion," Proceedings of the Combustion Institute, vol. 37, no. 1, pp. 57-81, 2019.

[4] E. Gregersen, "Bunsen burner," Encyclopædia Britannica, Inc, 2016.

[5] F. G. Roper, C. Smith and A. C. Cunningham, "The Prediction of Laminar Jet Diffusion Flame Sizes: Part II. Experimental Verification," Combustion and Flame, vol. 29, pp. 227-234, 1977.

[6] C. B. Stipe, B. S. Higgins, D. Lucas, C. P. Koshland and R. F. Sawyer, "Inverted co-flow diffusion flame for producing soot," Review of Scientific Instruments, vol. 76, no. 2, 2005.

[7] Argonaut Scientific Corporation, "Miniature Inverted Soot Generator," Argonaut Scientific Corporation, 2017. [Online]. Available: https://www.argonautscientific.com/products.

[8] A. Sobiesiak and J. C. Wenzell, "Characteristics and structure of inverse flames of natural gas," Proceedings of the Combustion Institute, vol. 30, no. 1, pp. 743-749, 2005.

[9] S. M. Mukarram, "Diffuse Two-Dimensional Line-of-Sight Attenuation method for Soot Concentration Measurements using a Pulsed LED Source and an Intensified-CCD Sensor Camera," National Research Council Canada, Ottawa, 2015.

[10] Ö. L. Gülder and A. E. Karataş, "Effects of carbon dioxide and nitrogen addition on soot processes in laminar diffusion flames of ethylene-air at high pressures," Fuel, vol. 200, pp. 76-80, July 2017.

[11] Engineering Toolbox, "Gases - Densities," 2003. [Online]. Available: https://www.engineeringtoolbox.com/gas-density-d_158.html. [Accessed 14 Sept 2019].

[12] Engineering ToolBox, "Gases - Dynamic Viscosity," 2014. [Online]. Available: https://www.engineeringtoolbox.com/gases-absolute-dynamic-viscosity-d_1888.html. [Accessed 14 Sept 2019].

[13] V. V. Mane, "An Effective Method to Reducing Smearing in Machining of Metallic Foams using Ice as an Infiltrant," lowa State University Digital Repository, Ames, 2016.

[14] Y. Liu, W. Zhou, X. Chu, S. Liu and K. S. Hui, "Feasibility investigation of direct laser cutting process of metal foam with high pore density," The International Journal of Advanced Manufacturing Technology, vol. 96, no. 5-8, pp. 2803-2814, May 2018. 
[15] IPPC, "Summary for Policymakers. In: Climate Change 2013: The Physical Science Basis. Contribution of Working Group I to the Fifth Assessment Report of the Intergovernmental Panel on Climate Change," Cambridge, 2013.

[16] P. L. a. C. Wang, "The Diesel Soot Particles Fractal Growth Model and Its Agglomeration Control, Kinetic Modeling for Environmental Systems," IntechOpen, 5 Nov 2018. 